\title{
Petani Kopi Bisang di Desa Tibussan Latimojong Luwu, 2013-2017
}

\author{
Harnita ${ }^{1}$, Muhammad Saleh Madjid ${ }^{2}$ Jumadi $^{3}$ \\ Prodi Pendidikan Sejarah Fakultas Ilmu Sosial Universitas Nnegeri Makassar, Indonesia \\ Email: ciciharnita25@gmail.com
}

\begin{abstract}
Abstrak
Penelitian ini bertujuan untuk mengetahui latar belakang munculnya petani Kopi di Desa Tibussan Kecamatan Latimojong, Dinamika Petani Kopi Bisang di Desa Tibussan Kecamatan Latimojong, dan kehidupan sosial ekonomi petani kopi di Desa Tibussan. Penelitian ini merupakan penelitian sejarah yang menggunakan metode sejarah melalui tahapan kerja yakni heuristic atau pengumpulan data, kritk sumber, interpretasi, historiografi atau hasil penulisan. Hasil penelitian ini menunjukkan bahwa komoditi kopi bisang ,di temukan Sudirman dan mulai diperkenalkan ke masyarakat Luwu oleh seorang bupati luwu yaitu Andi Mudzakkar yang sedang berkunjung kerumah kepala Desa Tibussan salah satu masyarakat Desa Tibussan. Kemudian Andi Mudzakkar menyebarkan biji kopi hasil pertanian bapak sudirman di setiap Luwu Expo. Sudirman pertama kali menyajikan kopi bisang kepada bapak bupati luwu yaitu cakka, karena kopi bisang dianggap istimewa oleh masyarakat Desa Tibussan jadi bapak sudirman menyajikannya langsung untuk cakka al hasil sejak tahun 2013 awal mulanya kopi bisang dikenal dan dianggap sebagai kopi orang luwu khusunya Desa Tibussan Kecamatan Latimijong hingga tahun 2017 semakin dipercayai sebagai kopi khas Latimojong. Setelah itu perekmbangan komoditi kopi yang dilihat dari produksi kopi di Desa Tibussan mengalami pasang surut yang disebabkan beberapa hal seperti factor cuaca, penambahan lahan baru, dan pergantian lahan pertanian kopi ke lahan lainnya.
\end{abstract}

Kata kunci : Petani, Kopi dan Tibussan

\begin{abstract}
This study aims to determine the background of the emergence of Coffee farmers in Tibussan Village, Latimojong Subdistrict, Dynamics of Bisang Coffee Farmers in Tibussan Village, Latimojong District, and the socio-economic life of coffee farmers in Tibussan Village. This research is a historical research that uses historical methods through work stages namely heuristic or data collection, criterion of sources, interpretations, historiography or writing results. The results of this study indicated that Sudirman coffee commodity was found by Sudirman and was introduced to the Luwu community by a luwu regent, Andi Mudzakkar who was visiting the house of the head of Tibussan Village, one of the Tibussan Village communities. Then Andi Mudzakkar distributed the Sudirman coffee beans to each of the Luwu Expo. Sudirman first presented coffee to luwu regent, namely cakka, because coffee bisang was considered special by the Tibussan Village community so Mr. Sudirman presented it directly to cakka al as a result since 2013 coffee was originally known and considered to be coffee of luwu people especially Tibussan Village, Latimijong Subdistrict Until 2017, it is increasingly believed to be a typical Latimojong coffee. After that coffee commodity development seen from coffee production in Tibussan Village experienced ups and downs due to several factors such as weather factors, the addition of new land, and the replacement of coffee farms to other fields.
\end{abstract}

Keywords: Farmers, Coffee and Tibussan 


\section{A. Pendahuluan}

Indonesia adalah salah satu Negara berkembang yang memiliki lahan pertanian yang cukup luas. Oleh sebab itu dapat dikatakan bahwa Indonesia merupakan Negara Agraris yang mana para penduduknya sebagian besar bekerja di bidang pertanian. Di Negara agraris yang memiliki sumber daya alam yang beraneka ragam yang memiliki wilayah yang cukup luas. Pertanian memiliki peranan yang penting baik di sektor perekonomian ataupun kebutuhan kebutuhan pokok atau pangan dengan semakin bertambahnya penduduk maka konsumsi pangan juga akan meningkat sehingga dapat meningkatkan perekonomian bagi petani. (Banowati, 2013)

Tanaman kopi diduga berasal dari Negara Ethopia.Pada abad ke-9, seorang pemuda bernama Kaldi tidak sengaja menemukan biji merah yang didapat dari semak belukar.Kaldi merasakan perubahan yang luar biasa setelah memakan biji tersebut.Lalu dia menceritakan hal tersebut kepada warga sekitarnya dan menyebar hingga ke berbagai daerah, biji mentah yang dimakan tersebut merupakan Coffe Bean.pada abad ke-10, biji kopi dimasukkan sebagai kelompok makanan oleh beberapa suku di Ethopia. (Naim, 1999)

Kopi merupakan bahan minuman yang banyak diminati oleh masyarakat dunia tak terkecuali masyarakat Indonesia. Hal ini dikarenakan, kopi memiliki aroma yang khas. Kopi merupakan bahan ekspor Indonesia non migas yang berkontribusi besar dalam peningkatan devisa negara, dan setiap tahun terus meningkat. Secara garis besar, kopi dibagi menjadi tiga jenis, yaitukopi Arabika, kopi Robusta dan kopi Liberika.

Salah satu pertanian yang ada di Negara Indonesia adalah perkebunanperkebunan atau plantation biasanya diusahakan didaerah yang mempunyai musim panas di dekat katulistiwa. Karena menggunakan manajemen seperti pada perusahaan Industri, maka perkebunan sering disebut juga Industri perkebunan atau Industri Pertanian.

Kopi Internasional dan tentunya pasaran kopi dunia tanpa pembatasan ekspor akan lebih menguntungkan bagi Indonesia, untuk bias ,mengusahakan perluasan pasar bagi jumlah produksi kopi untuk ekspor yang meliputi sekitar 400.00 ton setahun saat ini. (P.S.Siswoputranto, 1993)

Besarnya keuntungan yang diperoleh dari harga kopi yang terus meningkat tajam membuat banyak Negara untuk berlombalomba untuk meraup keuntungan yang besar dengan membuka lahan-lahan perkebunan kopi di negaranya maupun di Negara jajahannya. (Rahayu, 2015)

Kajian relevan dalam suatu karya ilmiah perlu untuk ditelusuri guna mencari tahu apakah ide pokok suatu kajian sudah diangkat oleh penulis lain atau belum. Penelitian ini berusaha untuk mengaji mengenai petani kopi bisang di Desa Tibussang diKabupaten Luwu.

Kajian relevan berupa buku ditemukan dalam bentuk buku, yang telah diterbitkan oleh beberapa orang penulis. Adapun kajian mengenai petani kopi dalam bentuk buku yang telah terbit pada umumnya membahas kopi internasional Indonesia secara keseluruhan. Tanpa secara spesifik membahas mengenai para petani kopi yang sampai sekarang masih bekerja sebagai petani tetap khusunya di desa tibussang kabupaten luwu.

Buku-buku tersebut diantaranya buku yang ditulis oleh seorang bernama P.S Siswoputro yang diterbitkan oleh Kanisus tahun 1993 yang berjudul kopi Internasional dan Indonesia, yang membahas tentang sejarah kopi yang ada di Indonesia dan perkembangan budidaya kopi serta komoditi kopi. Adapun buku yang ditulis oleh Yusnu Iman Nurhakim \& Sri Rahayu yang diterbitkan oleh Infra Pustaka yang berjudul Perkebunan Kopi Skala Kecil Cepat Panen, yang membahas tentang biji-biji kopi yang baik untuk dijadikan bibit dan memanen buah kopi dengan jangka yang ditntukan. 
Selain buku-buku yang membahas secara khusus mengenai kopi, digunakan pula buku-buku penunjang lain yang masih relevan dengan tema penelitian. Di antaranya buku dengan judul Bercocok Tanam Kopi yang diterbitkan oleh Kanisus tahun 1974, penulisnya adalah Girisonta. yang membahas cara penanaman biji kopi yang benar dengan kualitas yang baik serta tahap tahap yang sesuai dengan tata cara penanaman biji kopi. Buku dengan judul Budidaya Tanaman Kopi yang diterbitkan oleh aksara agraris kanisus tahun 1989 , penilsya Aak. Membahas tentang tanamantanaman kopi yang dapat dipanen dalam jangak waktu yang ditentukan karena semua jenis kopi memiliki biji yang berbeda-beda dengan jangka waktu panen yang berbeda pula. Buku yang ditulis oleh Dr. Bustanul Arifin yang berjudul Analisis Ekonomi Pertanian Indonesia yang diterbitkan oleh kanisus tahun 2004. Membahas tentang kehidupan ekonomi petani kopi di Indonesia yang merupakan masalah utama para petani, dimana nilai jual biji kopi turun naik. Buku dengan judul Diversifikasi Pedesaan yang diterbitkan oleh uip tahun 1995, penulisnya Dinyo Prabowo. Dimana buku ini membahas tentang pedesaanpedesaan yang memiliki suatu masalah dalam suatu lingkungan masyarakat guna menigkatkan kehidupan sosial ekonomi yang selalu menjadi masalah utama di Indonesia.

Adapun kajian relevan dari skripsi yang membahas tentang kopi dapat dilihat dari karya Elizabet Ratinian tahun 2011, Jurusan pendidikan sejarah UNM, Dengan judul perang kopi di Toraja. Pada pembahasannya Elizabeth memfokuskan kajiannya dengan perang kopi yang ada di Toraja menjadi pusat komoditi yang ada di daerah pallangga yang menjadi incaran para pedagang-pedagang Bone, Luwu, Sidenreng dan juga Sawitto dan inilah yang memicu terjadinya perang. (Ratiniman, 2011) Adapun jurnal dalam kajian relevan ini yang ditulis (Davis, 2006)

\section{B. Metode Penelitian}

Penelitian ini merupakan penelitian sejarah yang bersifat deskriptif analisis dengan tujuan untuk menemukan dan mendeskripsikan secara analitis serta menginterpretasikan terkait dengan Petani Kopi Bisang di Desa Tibussan Kecamatan Latimojong Kabupaten Luwu penelitian ini termaksud dalam kajian sejarah Agraris.

Dalam penulisan suatu karya ilmiah tersebut. Hal ini sering di disebut sebagai metode. Metode berbeda dengan metodologi. Menurut Kenneth D.Bailey, metode adalah tehnik penelitian atau alat yang digunakan untuk mengumpulkan data. (Madjid, 2008) Berdasarkan uraian tersebut di atas dapat disimpulkan bahwa metode sejarah merupakan cara atau tehnik dalam merekontruksi peristiwa masa lampau, melalui empat tahapan kerja yaitu heuristic (pengumpulan sumber), kritik sumber (eksternal bahan dan internal isi), interpretasi (penafsiran), dan historigrafi (penulisan Sejarah).

\section{Heuristik}

Heuristik merupakan langkah awal dalam melakukan penelitian sejarah, yaitu suatau kegiatan mencarin sumber-sumber untuk mendaptkan data-data atau materi sejarah serta segala yang berhubungan dengan topic penelitian. (Rochmat, 2009) Sumber sejarah tersebut dapat berupa catatan, tradisi lisan maupun dokumendokumen yang berhubungan dengan penelitian.

\section{Kritik}

Tahap kedua dalam penelitian sejarah adalah kritik sumber. Hasil yang ingin dicapai pada tahap ini adalah didapatnya sumber sejarah yang benar-benar memberikan fakta guna merekonstruksi masa lalu. Terdapat dua aspek yang harus diverifikasi yaitu Otentisitas atau keaslian sumber, dan kredibilitas atau tingkat kebenaran informasi dari sumber sejarah.

Penentuan keaslian suatu sumber berkaitan dengan bahan yang digunakan dari sumber tersebut, atau biasa disebut kritik eksternal. Sedangkan penyeleksian informasi yang terkandung dalam sumber 
sejarah, dapat dipercaya atau tidak, dikenal dengan istilah kritik internal. Setiap sumber sejarah diperlakukan sama, yakni diseleksi baik dari segi eksternal maupun internalnya. Tahap penyeleksiannya harus sistematis, yakni diawali dengan kritik eksternal dan kemudian kritik internal. Jika tahap pertama suatu sumber sejarah tidak memenuhi syarat sebuah sumber sejarah (dari segi otentisitasnya), tidak perlu dilanjutkan verifikasi berikutnya. (Madjid, 2014)

\section{Interpretasi}

Pada tahap ketiga peneliti harus menafsirkan data-data yang telah diperoleh. Proses menafsirkan memerlukan ketelitian dari seorang penulis untuk memilah data mana yang penting untuk tema penelitian dan data mana yang tidak berkaitan dengan penelitian.

\section{Historiografi}

Pada tahap terakhir ini, data-data yang telah diseleksi oleh peneliti melalui tiga tahapan sebelumnya kemudian dituliskan dalam bentuk kisah sejarah. Historiografi merupakan puncak dari segala-galanya dalam metode penelitian sejarah. Sejarawan pada fase ini mencoba menangkap dan memahami histoire realite atau sejarah sebagaimana terjadinya.

\section{Pembahasan}

\section{Petani Kopi Bisang di Desa Tibussang} Luwu

\section{a. Latar Belakang Petani Kopi Bisang di Desa Tibussan}

Kopi adalah salah satu hasil perkebunan Indonesia yang memberikan banyak pemasukan khususnya disektor perekonomian terutama di Desa Tibussan Kecamatan Latimojong Kabupaten Luwu, sehingga kesehjatraan petani kopi lebih meningkat.

Tanaman kopi merupakan komoditi eskspor yang cuckup menggembirakan karena mempunyai nilai ekonomis yang relativ tinggi dipasaran dunia. Sektor pertanian tumbuh sekitar 3.73 persen rata-rata per tahun pada periode 1968-2001, suatu angka yang tidak terlalu rendah. Peran subsektor pangan dan tanaman perkebunan cukup dominana dalam struktur pertumbuhan sektor pertanian tersebut sepanjang lebih dari tiga dasawarsa tersebut. (Arifin, 2004)

Aspek perkopian di Indonesia yang mendesak perlu digarap secara terus menerus, konsisten dan mantap mengacu untuk menumbuhkan citra baik Indonesia dalam perkopian dunia. Di pasaran dunia, Kopi Arabika adalah salah satu hasil komoditi-komoditi yang menjanjikan para pedagang Luwu untuk dapat memanen hasil dalam jumlah sangat besar, kopi Arabika biasanya dieksport melalui muara sungai sa'dang di Bugis Pinrang, keuntungan inilah yang dimamfaatkan oelh pedagang-pedagang Luwu untuk tetap Bertahan, dan ini di buktikan dari lamanya para pedagang-pedagang Luwu. (Ratiniman, 2011)

Kopi menjadi bahan perdagangan, maka dalam mensukseskan perkebunana Kopi mendapat kepercayaan dan tugas berat dari pemerintah untuk menghasilkan bahan export. Sebaba di negara-negara tertentu, terutama di Negara-negara Eropa, banyak orang yang suka minum Kopi, tetapi negaranya tidak menghasilkan, terpaksa harus membeli di Negara lain. (Aak., 1974)

Dengan hasil ekspor ini, Negara dapat memperoleh uang yang banyak, sehingga dapat dipergunakan untuk membeli alat-alat dan bahan-bahan industri yang di Negara kita belum ada. Tanaman kopi juga mempunyai fungsi sosial, sebab dengan adanya perkebunan Kopi yang besar itu, berarti peluang untuk memberikan pekerjaan bagi orang-orang yang berdekatan.

Petani Kopi di Desa Tibusssan sudah ada sejak zaman Belanda dimana pada waktu itu petani masih sangat kurang sekali, sebab dulu petani kopi peluang pasarnya masih sedikit dan kurang ditekuni oleh masyarakat Desa Tibussan, maka dari itu pertanian mengelolah Robusta dan Arabika. Petani Kopi di Desa Tibussang 
yang turut menentukan keberhasilan pembangunan pertanian didaerah tersebut. Hal ini dikarenakan yang menjadi objek pengembangan adalah petani kopi, sehingga dapat dikatakan bahwa petani merupakan unsur yang paling penting dalam proses pembangunan pertanian dan perkebunan. (Sudirman, 2018)

Kopi di Tibussan pertama kali ditanam oleh Lai Ballo pada tahun 1978 dan hingga saat ini masih menjadi komoditi utama masyarakat Desa Tibussan dalam bidang pertanian. (Ballo, 2018) Pada tahun 1978 orang pertama yang menanam kopi di Tibussan adalah Lai Ballo. Meskipun pada awalnya bukan hanya Lai Ballo yang diberikan biji kopi oleh Mamma, dalam pertumbuhan kopi yang ditanam Lai Ballo dan diketahui cocok dengan geografis di Desa Tibussan, barulah Sudirman yang mendapat biji kopi dari Mamma kemudian menanam biji kopi yang ia dapatkan, karena Sudirman ialah anak dari Lai Ballo sendiri. Lai Ballo menanam biji kopi yang ia dapatkan sebanyak 3 tiga liter di area perkebunan dengan luas 0,5 Ha. masa panen pertama Lai Ballo dengan hasil produksi 700-800 buah per sekali panen. Pada tahun 1991, Lai Ballo memperluas lahan pertanian kopinya dengan menanam kopi di dua tempat dengan luas 0,3 Ha dan 0,4 Ha. Hasil panen dari keseluruhan pertanian kopinya 1000-1200 bua per sekali panen. Pada tahun 1998, ia kembali memperluas lahan pertanian kopinya dengan menanam kopi di lahan seluas $1 \mathrm{Ha}$ di empat tempat dengan hasil produksi pertanian kopinya bertambah menjadi 2.500 buah per panen, dengan penggabungan lahan Sudirman dengan Lai Ballo. Pada tahun 2000 merupakan tahun terakhir Lai Ballo memperluas lahannya dengan menggabungkan lahannya dengan Sudirman yang tak lain adalah anaknya, kemudian di tahun 2000 Lai Ballo meyerahkan kebunnya kepada anaknya Sudirman untuk dikelolah. Namun setelah dilihat dari tahun ketahun masyarakat Desa Tibussan sudah banyak yang membudidayakan kopi karena terinspirasi dari Lai Ballo yang mendapat keuntungan setiap tahunnya dari hasil pertanian kopinya dari tahun ke tahun. Setelah Sudirman yang Mengelolah kebun Lai Ballo pada Tahun 2000 pada saat itu pula kelompok tani barulah dikembangkan pada tahun 2000 tetapi sebelumnya pada tahun 1999 Sudirman awalnya sudah Membentuk Kelompok Tani tetapi belum dikembangkan karena keterbatasan dana. Dimana kelompok tani itu diketua oleh Sudirman sendiri sebelum diangkat menjadi kepala Desa pada tahun 2011 sampai 2 periode. Setelah Sudirman menjabat sebagai Kepala Desa barulah ketua kelompok tani digantikan oleh Hasbullah.

Perubahan tersebut terjadi akibat perubahan pola fikir msyarakat dalam pemamfaatan sumber daya alam yang tersedia di lingkungan tersebut. Seperti halnya yang terjadi di Desa Tibussan, setelah dikenalnya kopi 1980-an dari tahun ke tahun msyarakat Desa Tibussan mulai melirik komoditi kopi sebagai komoditi unggulan untuk dikembangkan. Hal tersebut dimulai sejak masyarakat di Desa Tibussan mendapat sosialisasi dari masyarakat jawa yang telah terlebih dahulu mengembangkan tanaman kopi. Selain itu, faktor lain yang melatar belakangi perkebunana Kopi di Desa Tibussan yaitu daerahnya memiliki topografi atau bentang alam pengunungan dan cuaca yang sejuk yang sangat cocok dengan tanaman kopi sehingga masyarakat menjadikan perkebunana kopi sebagai mata pencahaian Utama.

Setalah Petani Kopi Bisang sudah memiliki sedikit-demisedikit lahan untuk bertani mereka terus mengembangkan pemamfaatan sumber daya yang ada. Dimana pada tahun 1980-an masyarakat Desa Tibussan mengalami peningkatan sampai kopi Bisang dikenal oleh masyarakat lain, walaupun hanya daerah Kabupaten Luwu saja.

Masyarakat petani-pekebun kopi perlu mengikuti perkembangan mutakhir perkopian dunia, dimana iklim sangat 
berpengaruh pada pertumbuhan tanaman dan produksi tanaman kopi,perubahan iklim dapat memicu datangnya hama dan serangan penyakit pada tumbuhan kopi, untuk mendapatkan produksi yang baik diharapkan Petani Kopi di Desa Tibussan para petani Kopi bekerjasama dengan pengelololah pertanian yang ada di Kabupaten Luwu untuk lebih mengetahui cara-cara bertani Kopi yang benar. Agar para petani tidak salah dalam pemeliharaan kebun Kopi yang mereka garap sebab utuk mendapatkan biji kopi yang baik adalah dari cara menanam dan merawat tumbuhan kopi masyarakat perlu dibimbing dengan membentuk kelompok tani Desa Tibussan. Hal inilah yang mendorong para Petani di Desa Tibussan untuk fokus dalam perkebunan kopi dimana tempat, lokasi dan tekstur tanah yang mendukung dimana sayur-sayuran, ubi-ubian, cengkeh dan kopi sangat cocok ditanam di daerah yang sejuk seperti Di Desa Tibussan kecamatan Latimojong.

\section{b. Terbentuknya Kelompok Tani di Desa Tibussan}

Kelompok tani di Desa Tibussan mulai ada sejak tahun 1999 dan baru dikembangkan pada tahun 2000 ketuanya ialah Hasbullah, dan kelompok tani itu diberi nama Petani Memanggil sampai sekarang dimana pada saat itu petani belum terlalu banyak dan kurangnya pasilitas yang menjadi hambatan utama para petani di Desa Tibussan Kecamatan Latimojong Kabupaten Luwu

Petani di Desa Tibussan sebelum di aktifkannya atau sebelum terbentuknya kelompok tani para petani di Desa Tibussan hanya bertani secara individu (sendiri-sendiri) itulah yang menyebabkan masih kurang kerja samanya sesama petani, tetapi setelah dibentuknya kelompok tani masyarakat Desa Tibussan setiap Minggu melakukan gotong royong bersama. (Syarif, 2019)

Setelah kelompok tani di Desa Tibussan terbentuk masyarakat mendapat perhatian khusus dari Dinas Pertanian Kabupaten Luwu masyarakat Desa
Tibussan sangat memiliki rasa kebanggaan tersendiri sebab mereka selalau dapat bantuan-bantuan dari pemerintah melalui kelompok tani.

Di samping itu petani Kopi Bisang setiap tahun menggalang kerja sama yang baik, para petani membuat satu tempat penampungan Kopi Bisang dimana tempat atau gudang penyimpanan Kopi itu khusus untuk masyarakat Desa Tibussan, gunanya agar setiap petani setelah habis panen Kopi, para petani tersebut menyimpan hasil panen digudang yang sudah di buat agar Biji Kopi Bisang terkumpul banyak dan pada saat dijual harganya terkumpul dan dibagi rata agar tidak ada kecurangan. Disetiap kerjasama antara para petani dibutuhkan rasa saling percaya dan kejujuran hal itulah yang membuat para petani Kopi Bisang setiap tahun semakin mengalami peningkatan dalam kerja sama yang bisa dikatakan kekeluargaanya sangat terjaga . (Masri, 2019)

Di tahun 2013 bapak Bupati Luwu H.Andi Mudzakkar memperkenalkan Kopi Bisang di Kecamatan Latimojong Kabupaten Luwu, Menurut Andi Mudzakkar Kopi Bisang ini tergolong Kopi yang unik namun keterbatasan Ekonomi yang dialami oleh masyarakat Desa Tibussan yang menjadi masalah utama, pada saat itulah bupati Luwu mempunyai ide untuk mengenalkan Kopi Bisang sedikit demi sedikit walalupun awalnya diperkenalkan hanya di Luwu saja tetapi itu satu hal yang baik karena mendapat respon yang sangat baik dari masyarakat setempat.

Diawali dengan pengenalan oleh bupati Luwu, setiap melakukan pameran atau Luwu Expo yang diadakan 2 tahun sekali stand Kopi Bisang yang terletak pas ditengah dikelilingi oleh stand-stand yang lain, stand itu menjadi basecamp Bupati Luwu dan para tamu yang ada disitulah dimulai dikenal Kopi Bisang, hal ini yang menguntugkan Kelompok Tani Desa Tibussan sebab setiap adanya acara terkhusus acara bapak bupati sendiri baik 
didalam Sulawesi maupun diluar, selalu membawa nama dan cita rasa Kopi Bisang tersebut bahwa Kopi Bisang adalah Kopinya orang Luwu. Maka dari itu kelompok tani Desa Tibussan benarbenar memafaatkan peluang besar karena dulunya kopi mereka hanya dijual dengan harga yang murah tetapi sekarang pembelian biji Kopi Bisang itu sudah dibatasi dan tidak diberikan secara bebas sebab petani Kopi Bisang sudah memiliki penyimpanan tersendiri.

\section{c. Faktor Pendorong pertanian Kopi di Desa Tibussan}

Beberapa factor member kesempatan bagi petani untuk mengembangkan pertanian kopi. Bibit kopi yang sangat mudah diperoleh, yaitu hanya dari biji kopi yang sudah dipetik lalu dikeringkan lalu di rendam kemudian dapat langsug ditanam, dan perawatan tanaman kopi juga tergolong mudah. Sumber daya alam yang memadai juga memberikan peluang untuk mengembangkan pertanian kopi di Tibussan. Sebelum adanya pertanian kopi, banyak lahan di Tibussan yang hanya di isi pohon-pohon besar dan kebanyakan lahan perkebunan yang hanya ditanami umbi-umbian. Selain karena Bibit kopi yang mudah didapatkan dan cara penanamannya mudah, serta keadaan ekonomi masyarakat Tibussan, Faktor lain yang menyebabkan petani kopi semakin bertambah di Desa Tibussan yaitu keadaan geografis wilayah Tibussan.

Produkasi dan mutu hasil buahbuahan dipengaruhi oleh banyak factor, diantaranya ketinggian tempat yang erat kaitannya dengan suhu udara, kedaan iklim dan tanah. Sama halnya dengan tanaman kopi yang dapat ditanam di dataran rendah muali dari tanah ngarai, daerah pesisir dan tepu pantai hingga kedataran tinggi di lereng-lereng bukit atau pegunungan sampai pada ketinggian 800 meter diatas permukaan laut.

Tanaman kopi di dataran tinggi akan tumbuh baik pada daerah yang banyak mendapatkan curah hujan anatar 1,000 $\mathrm{mm}$ sampai $4,000 \mathrm{~mm}$ per tahun.
Tanaman kopi sulit tumbuh pada daerah yang mengalami musim kering yang lama. (Aak, 1974) Pada tahun 2010 tingkat curah hujan di Latimojong mencapai $2.531 \mathrm{~mm}$ dan pada tahun 2014 mencapai 1,605 mm. (Statistik., 2015) Artinya iklim di Latimojong cocok untuk tanaman kopi. Syarat tumbuh kopi juga sangat dipengaruhi oleh suhu, kelembapan dan jenis tanah. Oleh karena itu, tanaman kopi tidak dapat tumbuh dengan baik di sebagian wilayah Luwu hal ini disebabkan karena suhu, kelembapan, jenis tanah serta ketinggian di Kabupaten Luwu berbeda-beda.

Petani kopi pada tahun 2012 memfokuskan kegiatan penguatan ekonomi masyarakat di Desa Tibussan dengan kaderisasi petani kopi melalui program traning perawatan kebun para petani kopi dan proses pasca panen kopi.

Selain itu masyarakat Desa Tibussan juga melanjutkan program rutin pendistribuan bibit kopi kepada para petani lainnya atau masyarakat umum untuk mulai menanam kopi. Kepala pertanian juga membantu akses agar petani mendapatkan kepastian pasar untuk penjualan green bean (biji hujau) mereka dengan harga yang adil bagi petani dan pihak pembeli.

Pendistribusian bibit kopi telah berhasil mendistribusikan 400 pohon bibit kopi untuk pengembangan kopi di Desa Tibussan Kecamatan Latimojong, yang cukup jauh di pedalaman dan berbatasan langsung dengan kabupaten Enrekang.

Sementara dalam satu bulan yang sama, kepala pertanian Kabupaten Luwu di Desa Tibussan melakukan pemantauan lewat kunjungan ke kebunkebun Kopi tersebut dan mulai menyederhanakan modul pelatihan perawatan dan proses pasca panen agar memudahkan pemahaman petani. Hasil pantauan tersebut dievaluasi pada bulan Desember sekaligus memberikan intensif sebagai wujud apresiasi terhadap 
komitmen kerja petani untuk perwatan kebunnya.

Secara keseluruhan perawatan kebun khususnya pengenalan empat teknik pengolahan pasca petik kopi dirasakan mamfaatnya oleh para petani. Karena dengn adanya traning yang diadakan setiap 6 bulan sekali memeberikan keuntungan bagi para petani Desa Tibussan dimana mereka setiap tahunnya memiliki peningkatan baik dari penanaman biji kopi maupun saat panen Kopi tibah.

Dengan adanya traning yang diikuti setiap masyarat khususnya Desa Tibussan para petani mengalami perkembangan yang dikatakan cukup baik dimana tahun 2013 kopi mereka sudah lebih banyak dikenal oleh masyarakat luar Desa Tibussan. Tetapi lebih dikenal ketika bapak bupati luwu H. Andi Mudzakkar memperkenalkan Kopi BIsang ke luar Kabupaten luwu hingga sampai tahun 2017 pemesanan kopi bisang masih dibatasi karena masyarakat Desa Tibussan sudah memiliki tempat penampungan biji kopi yang sudah dipanen dan disimpan lebih lama agar mendapatkan aroma dan rasa yang berbeda dari Kopi yang lain.

Kopi Bisang sampai sekarang pemesanan masih terbatas sebab biji kopi yang baru dipanen belum bisa diolah karena untuk mendapatkan aroma dan rasa yang baik biji kopi harus di diamkan lebih lama dengan jangka waktu 1-2 bulan, maka dari itu sekarang yang dijaga ialah orang-orang yang menjual biji kopi dengan label kopi bisang harus diketahui lebih jelas karena sekarang sudah banyak yang memalsukan kopi dengan nama Kopi bisang padahal itu bukan produk kopi bisang yang asli, maka dari itu dapat dikatakan bahwa dari tahun 2013-2017 petani kopi bisang mengalami peningkatan yang luar biasa sebab Kopi Bisang sudah dikenal di luar Sulawesi.

Untuk itu perlu diketahui bahwa Petani Kopi bisang dulunya sangat sedikit karena pemesanan kopi yang kurang dan harga yang tidak menentu tetapi setelah melakukan tahap-tahap dari menanam sampai memanen Kopi biji yang diproduksi memiliki nilai jual yang tinggi sebab para petani di Desa Tibussan sudah mengikuti training yang diadakn setiap 6 bulan sekali agar memiliki pemahaman yang lebih dan tata cara panen dan pengolahan yang benar.

Dengan diperkenalkannya Kopi Bisang Kelompok Tani di Desa Tibussan mendapat perhatian lebih dari kepala pertanian Kabupaten Luwu sebab Kopi Bisang dikenal dengan cirri khas Kopi Orang luwu yang sudah dikenal oleh masyarakat sul-sel maupun diluar sul-sel.

Perkembangan Petani Kopi Bisang hingga tahun 2018 sudah mencapai 85\% dimana petani kopi semakin bertambah jumlahnya dan lahan pertanian semakin bertambah yang digarap untuk membuka perkebunan kopi, dimana ditahun ini setiap petani memiliki luas tanah 1,5 hektar tiap petani terhitung dari kepala keluarga berjumlah \pm 150 petani yang ada di Desa Tibussan Kecamatan Latimojong Kabupaten Luwu

\section{Kesimpulan}

Berdasarkan uraian pembahasan yang telah dipaparkan pada halaman-halaman sebelumnya, maka kesimpulan yang dapat diangkat sebagai berikut:

Dinamika petani kopi dapat dilihat dari persediaan lahan dimana luas lahan setiap petani di Desa Tibussan berjumlah rata-rata 1,5 hektar tiap petani dari jumlah 150 petani. Sistem pertanian kopi di Tibussan terdiri dari lima tahap yaitu penyediaan bibit, pengolahan tanah, penanaman, pemeliharaan, serta pemetikan. Namun luas lahan dan proses pemeliharaan berperan penting dalam hasil yang didapatkan kurang lebihnya biji kopi yang dihasilkan.

Keadaan sosial ekonomi petani kopi di Desa Tibussan kecamatan Latimojong, mengalami peningkatan. Seperti dilihat pada segi pendidikan, dengan bertani kopi masyarakat Desa Tibussan dapat memenuhi kebutuhan sehari-hari mereka, 
membagun rumah serta untuk membiayai ank-anaknya bersekolah baik di tingkat SD, SMP, SMA, maupun Perguruan Tinggi.

\section{E. Daftar Pustaka}

Aak., 1974. Bercocok Tanam Kopi. Yogyakarta: Kanisus.

Aak, 1974. Bercocok Tanam Kopi.. Yogyakarta: Kanisus.

Ahmadin., 2013. Metode PenelitianSosial.. Makassar: Rayhan Intermedia.

Arifin, B., 2004. Analisis Ekonomi Prtanian Indonesia. Jakarta: Kanisus.

Ballo, L., 2018. Wawancara [Interview] (November 2018).

Banowati, E. d. S., 2013. Geografi Pertanian. Yogyakarta: ombak.

Davis, 2006. Kopi excels. Jurnal Bumi, Volume 152.

Madjid, A. R. H. d. M. S., 2008. .Pengantar Ilmu Sejarah.. Ujung Pandang: Rayhan Intermedia.

Madjid, A. R. H. d. M. S., 2014. Pengantar IImu Sejarah.. Yogyakarta: Ombak.

Masri, 2019. Wawancara di Desa Tibussan [Interview] (Februari 2019).

Naim, M., 1999. Secangkir Kopi dalam Sepenggal Sejarah. s.l.:tempo.

P.S.Siswoputranto, 1993. Kopi Internasional dan Indonesia.. Yogyakarta: Kanisus.

Rahayu, Y. I. N. \&. S., 2015. Depok: InfraPustaka.

Ratiniman, E., 2011. "Perang kopi di Tanah Toraja.. In: Skripsi. Makassar: Universutas Negeri Makassar, p. 1.

Ratiniman, E., 2011. "Perang Kopi di Tanah Toraja”.Skripsi. Makassar: Universitas Negeri Makassar. Hal,79. In: Skripsi. Makassar: Universitas Negeri Makssar, p. 79.

Rochmat, S., 2009. Ilmu Sejarah Dalam Persfektif Ilmu Sosial. Yogyakarta: Graha Ilmu.
Statistik., B. P., 2015. Kecamatan Latimojong Dalam Angka 2016.. In: Enrekang: BPS Kabupaten Luwu, p. 88.

Sudirman, 2018. Wawancara [Interview] (minggu November 2018).

Syarif, 2019. Wawancara [Interview] (Februari 2019).

Usman, H., 1966. Metodologi Penelitian Sosial. Jakarta: Bumi Aksara. 